\title{
ROLE OF INDIGENOUS KNOWLEDGE IN MANAGING FLOODS
} PROJECTS

\author{
Jamshid Ali Turi' $^{1}$; Mushtaq Ahmad ${ }^{2}$; Mohamed Ibrahim Khalifa Haloul ${ }^{3}$ \\ ${ }^{1,2}$ University Engineering Technology (UET), Peshawar, Pakistan \\ ${ }^{3}$ Faculty of Engineering Management, University Putra Malaysia (UPM), Malaysia \\ ma_5099@yahoo.com
}

\section{Original Scientific Paper doi:10.5937/jouproman7-21018}

\begin{abstract}
Climate change is increasing the frequency of disasters in the world. Accordingly, disaster management strategies are also changing. The UN has focused on acknowledging the Indigenous Knowledge in disaster management strategies. In this study, the village Khursheed in District Sargodha has been focused due to facing frequent floods since decades. They have developed some methods to counter floods. The study was qualitative containing three focus group discussions and thirty interviews, reveals that villagers have devised their own flood forecast and early warning systems. The indigenous methods of constructions of buildings and agricultural techniques have rendered the village more resilient. The elevated spiritual level has enhanced their immune system to face floods. The government needs to devise local level disaster management strategies which should incorporate indigenous and modern knowledge.
\end{abstract}

Keywords: Climate Change, Disaster Management, Indigenous knowledge, Climate change, National Disaster Management Authority (NDMA)

\subsection{Introduction}

Pakistan is one of the badly affected countries by climate change as stated by The Intergovernmental Panel on Climate Change (IPCC) (Abid et al., 2016(a); Abid et al., 2016(b)). Diverse disasters are hampering the pace of socio-economic development of Pakistan. The frequency of disasters is going to increase in the future. The last two decades have witnessed some major earth quakes, floods and migration issues in the whole world (Cheeseman, 2016; Mohamed et al., 2019). Pakistan is not an exception either. Pakistan is a disaster-prone country which faces diverse disasters. However, the flood is the major disaster which Pakistan has faced in recent years and likely to bear more frequently in the future (S.Chaudhury, et al., 2016). Therefore, Pakistan has established National Disaster Management Authority (NDMA) and Earthquake Reconstruction and Rehabilitation Authority (ERRA) to counter disasters. Yet they are unable to control the disasters and advancement up to the mark would need high budget where country is under developing model. Therefore, precautions direly needed for enhancing the capacity of the people and organizations to protect themselves from all kinds of disasters (Abid et al., 2016 b). Diverse strategies and techniques have been adopted to counter floods in Pakistan. Indigenous knowledge strategies are local, viable, feasible, cost effective and easily implementable.

Therefore this paper established the local techniques and knowledge to cater for better from the catastrophic situations. 


\subsection{Objective of the Study}

The study's objective is to investigate and discover the practices and their applications of Indigenous Knowledge to manage floods in the village Khursheed (Pakistan). The focus is on disaster risk reduction techniques adopted by the local community.

\subsection{Research Questions}

1. What are the local methods to forecast flood?

2. What are the local methods of early warning systems in the area?

3. What are the local methods and techniques to protect your houses and household items from floods?

4. What are the local methods and techniques of protecting your livestock and crops from floods?

5. What are the local methods the method to protect family from the flood?

\subsection{Literature Review}

The world has faced a significant social, environmental and economic transformation in previous decades. The recent changes in world scenarios contain some negative as well as positive impacts (Main, et al., 2015). It leads to the growth, sustainability and development which are better for development. However, disruption and destabilization in the socioenvironmental systems reflect the negative impact. Natural disasters epitomize some of the recent and rapid disastrous changes on the face of earth. Sometimes it takes hardly minutes to destroy cities and country (Batool, 2017; Raza et al., 2017). The managing director of internal Monitoring Fund (IMF) declared the climate change as the biggest challenge of $21^{\text {st }}$ century during his speech in the World Economic
Forum held in Davis (Ganchi et al., 2016; Batool, 2017). Besides, The Intergovernmental Panel on Climate Change (IPCC) warns that the global warning may be increased from $1.1^{\circ} \mathrm{C}$ to $6.4^{\circ} \mathrm{C}$ during $21^{\text {st }}$ century. This will result a raise sea level up to 0.07 meter. The burgeoning population, urbanization and increasing vulnerability to climate change are some of the clear indications that a disastrous flood or cyclone may effect billions of people (shakir et al., 2010; Ganchi et al., 2016). Unfortunately every year more than 226 million people are affected by disasters. The economic cost of disaster was around $\$ 1$ trillion during 2000 to 2010. However, increase of spending in disaster risk reduction strategies can reduce the economic and human loss. Contrary to that, a paltry portion of $0.1 \%$ and $0.7 \%$ of total humanitarian aid was spent on disaster risk reduction strategies in 2001 and 2008 respectively (Hassan \& Hassan, 2017; Abid et al., 2016).

\subsection{Conceptual Framework}

In the flood hit area people take some precautionary safety measures to protect themselves from the floods. When a flood hits, they resort to their local knowledge methods and knowledge to rescue themselves and their belongings from the floods. The local or Indigenous Knowledge has been developed by the dwellers through generations (Qasim et al., 2017). 


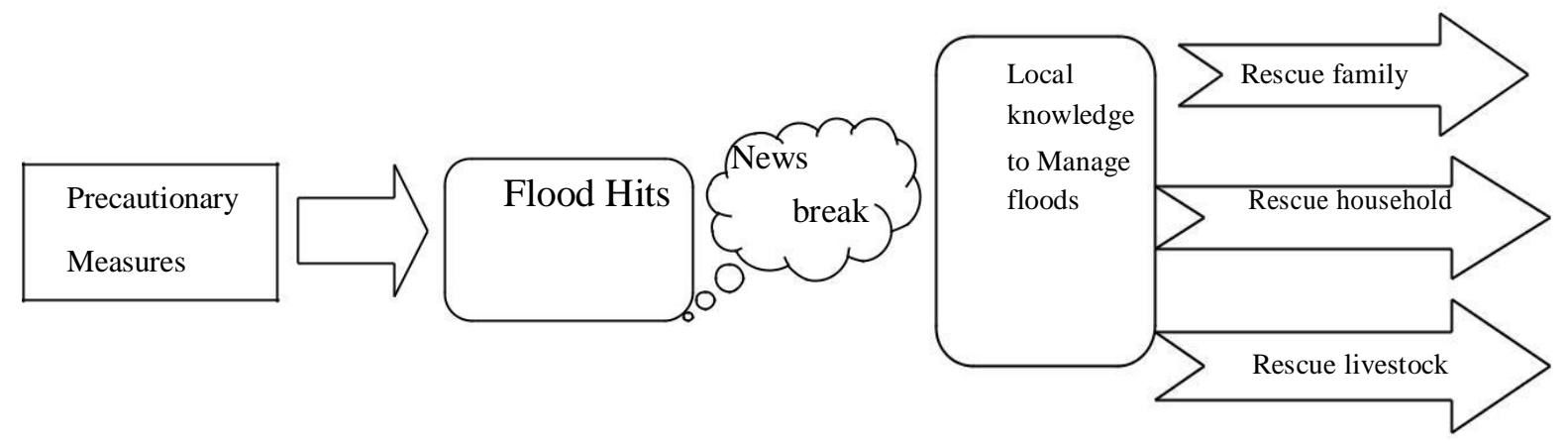

Figure 1: Conceptual Frame Work

The Asia Pacific region has diverse and rich in Indigenous Knowledge as this is an ancient civilization as well as it has multi-hazard zone historically. The area possesses diverse geocultural communities who are not so advanced and developed that it can use modern technology to manage natural disasters (Cheong et al., 2017). Therefore, they should rely on Indigenous Knowledge to overcome the natural disasters. In disaster-prone areas people resort to diverse warning systems to predict and disseminate warnings to evacuate the area or take appropriate measures to reduce the risk of prospective damage (Ali \& Bajracharyar, 2017; Hassan \& Hassan, 2017). For instance, Indian tribe Onge left their area before tsunami hit them. Their elders observed the changed behavior of birds and insects (Qasim, et al., 2017; Shakir et al., 2010). Similarly, a Jawara tribe in India was also safe as they left the Iceland and took refuge on a hilltop as the sudden dizziness of a young guy indicated the possibility of earthquake tremors (Butt et al., 2015). In Japan area of Saigasaki and Tano observed the speedy eating of animals and swallowing the grains warned them to take appropriate measures to reduce the damage from typhoon. The same community observes the nests-knitting honeycombs and predicts disasters accurately (Jabeen et al., 2015; Ali \& Bajracharyar, 2017). In Indonesia, Simeulue community rushed towards a hilltop and was safe though it was situated near to the epicenter of 2004 tsunami. The tsunami hit the area right after their evacuation. In fact, the Indigenous Knowledge of buffalo's action was immediately alert them (Memon et al., 2016; Batool, 2017). Similarly, in Indonesia people used the colors of clouds to determine the kind of rain or hailstone etc. The position of the moon helps them to determine the expected rains. They can predict the rainy season through the position of the sun (Zaheer et al., 2016; Cheeseman, 2016). Likewise, the direction of wind gives them indication of hot or cold weather.

Beating on drums, sounding horns and whistling are some of the examples of announcing impeding disaster. Early warning system (EWS) was installed with the help of Indigenous Knowledge was so successful in Bangladesh area of Khulna division that it has saved \$41 on just spending \$ 1 (Butt et al., 2015).

The government of Pakistan is concerned; it has been criticized for not being proactive resulting great loss. However, in many rural areas of Pakistan, people resort to local or Indigenous Knowledge to manage disasters (Kumbhar et al., 2018; Zaheer et al., 2016). 
These methods can offer a good model for disaster risk reduction and rescue strategies in some other affected areas as well. It is highlighted that in Chitral (Pakistan) locals learned to interpret early signs of potential flash floods. These kinds of signs consisted of colors, smell and mountain behavior. These practices are being exercised with great precision (Shah et al., 2015). For instance, more than one hundred houses were destroyed due to glacial lake flood in village Brep but there was no loss of life as they accurately interpreted the signs and village was evacuated timely. Similarly, in July 2006, the locals warned an engineering company to shift their installation as there was threat of flood as per local knowledge but the company did not take it seriously which resulted loss of life and equipment's worth millions of rupees (Cheong et al., 2017; Mahmood, 2017). Similarly, a research study conducted in Lepcha, discovered that some of the folklore of the area had useful knowledge of nature and natural disaster management. The study suggests that the knowledge may be incorporated into the modern scientific knowledge of disaster management as the techniques are good, cost effective, participatory and sustainable. Some of the earlier studies discovered that there were evidences of mixtures of local practices and scientific knowledge in managing disasters adopted by some organizations were successful experiments (Zarmina \& Zarmina, 2014; Ganchi et al., 2016). Conventional and ancient buildings are normally more resistant to disasters than new ones. For instance, during many disasters, churches, mosques, temples and other old vernacular buildings survived due to their robust nature of construction (Ganchi et al., 2016). The front shapes of such buildings are pointed so that the push impact of flood water can be minimized. Besides, mangroves and some other plants and trees are planted around houses to mitigate the flood impact and land erosion. These mangroves and other plants not only protect buildings but protect household items and livestock stuff. In some Indian, people dump their household items in a trench. Contrary to this, in some Chinese flood prone areas, community has prepared a platform at a high altitude where flood water cannot reach (Main, et al., 2015). Agro-pastoral tribes of Maasai in Africa keep on rotating, grazing and vegetation areas to conserve vegetation, fertility and water management in drought season. In some parts of India have seedbeds (Dhap or Baira) are constructed in waterlogged conditions for cattle refuge. Bamboo fencing and grass planting are used for earthen embankment to reduce flood erosion. A unique construction and style of three-meter-deep and seventy $\mathrm{cm}$ wide foundation trenches filled with stones, are common in Purola area of Utterkhashi district in India. The buildings are normally 2.30-meter-high above the surface of earth. This very style protects the buildings from floods (Zarmina \& Zarmina, 2014). Besides, the plantation of trees like Thysonolaena is common as it gives protection from land sliding. Besides, house roofs are covered with grass to insulate them against heat and rain. Besides, the fish ponds are covered with a net to stop the fish to jump out of the pond during floods (Khan et al., 2016). They perform many unique and different rituals like dancing, singing, and conducting marriages between frogs and chickens etc to influence the natural phenomena. These are the part of their belief and culture system. Furthermore, these are the sources of entertainment as well. The festivity factor is very important to enhance the resilience of the people (Ganchi et al., 2016).

In Bangladesh the practice of floating gardening had great positive impacts on the affected communities as it enhanced nutritional security, household income and land use capacity. 
It strengthened the resilience of vulnerable community to floods. However, the floating gardening is unsuitable for open waters (Qasim et al., 2017). Likewise, in some floodprone areas of Bangladesh and India, people have prepared platforms in the trees to provide protection and shelter to hen and some other birds during floods. Other animals like cow and buffaloes are shifted to some safer places specially built for castles. These places or platforms are called Tharas. The flood normally takes three to four days to let the people to resettle themselves. When the flood water is down, people start settling down again in their houses (Batool, 2017). Research findings indicate that social support networks, serving others, Hakka spirit, self-relia nce, resource availability, governmental agencies, preparedness, acceptance, and spirituality have direct and positive impacts on disaster resilience (Ganchi, Shakoor, Thaver, Khan, \& Janjua, 2016). Post-disaster life events and experience of natural disaster have direct but negative impacts on disaster resilience. Preparedness and resource availability are associated with governme nta 1 agencies. Resource availability has a direct and positive impact on self-reliance. Post-disaster life events may weaken social support networks. In some of the villages in Pakistan, the sacks full of sand are used to protect cushion and strengthen erosion of land during rain and floods.

\subsection{Research Methodology}

The research is qualitative. The triangulation and content analysis approach was adopted to enhance the reliability of the study and Emic approach was used applied to analyze the data so that the actual response of the respondents should be reflected in the analysis. Preliminary, some unstructured and informal interviews and discussions were conducted with the population under study. It helped identifying three major themes to be investigated in detail. Open-ended questionnaire was designed to further investigate the themes identified initially. Open-ended questionnaire is good for a study where respondents have diverse views and reflections regarding themes under study. Beside this it gives liberty to express respondents to present diverse opinions. In this research three focus group discussions were conducted to investigate the issues under study.

\subsection{Sample selection}

Convenient sampling has been used for interviews to get opinions from respondents. This sampling technique is cost effective, faster and supportive to collect data from diverse group of people. Thirty interviews were conducted and three focus group discussions were arranged. In each group, diverse members were selected to form the group. They belonged to different socio-economic and educational background like teachers, religious preachers, students, agriculturalists, elders of the village, laborers and Hakeem.

The area of the research study was village Khursheed. It is situated in District Sargodha. On the bank of river Jhelum, this village is hit in every flood. The village is around $10 \mathrm{~km}$ away from Islamabad-Lahore motorway near Bhera service area and interchange. The respondents were Punjabi speaking. Therefore, the questionnaire was translated into Punjabi language to make the respondents understand. Colloquial expressions and using indigenous of the old men were of more value regarding indigenous knowledge. The views and expressions of the respondents regarding themes under study were recorded and analyzed using content analysis and Emic approach which best support Phenomenological study design. 


\section{2 $\quad$ Flood Predictions Methods}

There are various methods and techniques which had been applying to foresee and guesses the floods in the area. Majority of the elder responded that after four or five years, there is a natural cycle of flood. When four consecutive years pass without flood, people are almost sure that the next year flood will hit the area. Therefore, they prepare themselves accordingly. Young and educated residents believed the climate change is the major reason behind unscheduled rain and floods. They also pointed out past two decades the frequency of flood has increased. However, majority of the elders says that floods frequency is the cause of their sins. So, they relate this phenomenon with their belief system. Whenever, there is a murder case or quarrels among the villager's increase, the elders warn and foresee that the flood will hit them this year. It's a part of their belief system that Nature/Allah inflicts punishment on them. Therefore, they keep on preaching each other to be pious and abstain from sins. Specially, they believe that Allah will never forgive if someone kills other human being. Some of the elders believed low rainfall in winter is another indication that summer will receive more rain. Heavy rainfall often causes floods. Therefore, the natives keep on watching down-pour pattern all the year round. Any change in the routine pattern of rain warns the people. Similarly, if May and June are dry and hotter than normal, there are chances of more rains which may result floods in the area.

The weather intensity level is another indication of prospective floods. The higher temperature than previous years in May and June cause heavy rain which is a clear indication of floods.
Many of the elders were optimistic about the floods as well. They have belief that the nature helps increasing their land-fertility. Flood water carries the natural salts and fertilizers which add to the land. As a result, per acre production is increased. So, whenever there is a less agriculture outcome in a year, they predict that the next year flood will hit the area and bring more useful salts and fertilizers. Several respondents told that the death and disease rate of humans and animals is another indication of prospective flood. They start urging each other to be more disciplined in their religious practices to protect themselves from expected flood in the future. Similarly, if there is an act of injustice and cruelty is committed by someone, they curb the responsible person and blame him/her for future flood. It indicates that God would be unhappy with the people; consequently, flood is likely to occur.

The birds' nesting pattern is another clue for them to profess the future flood. According to many elder's participants in focus group told if birds choose to knit their nests on higher places in the trees, it is an alarming for them. Inhabitants believe that birds can sense the future unpleasant incidents. Nature informs them in advance. Therefore, they shift their nests up to higher places. Besides, the wild dogs and cats start moving from the area before the flood hits the area. These are clear indication that flood is going to hit the village. Some elders stated that they could foresee the flood while observing waste of animals as well. Cow and buffalos eat less and develop some digestive system problems. Similarly, some birds like crow start flying away from the area.

Some of the elder women responded that there is a strange silence three or four day before the flood hits the area. These women claimed that they could sense this silence and accurately predict the upcoming floods. 
These respondents believe that every physical thing can hear and respond accordingly. Nature communicates with them. Many of the respondents expressed that many moles, burrowing animals, reptiles and some other creatures which live under ground and rarely come out on the surface, often come out and this is again an indication that a disaster like earthquake or flood is going to hit the area. Similarly, some mammals like cat leave the area prior to the floods. However, the younger generation responded bit differently. They rely more on modern trends and techniques; information technology is the modern 'oracle'. Majority of people now rely on electronic and print media to know about the prospective floods in the village. Media keeps on updating the water level in dams on the river Jhelum. In the months of July and August, residents of the village religiously watch $\mathrm{TV}$, listen radio, read newspapers and young university students follow social media to be updated of weather conditions in upstream. If there are news of excessive rains, residents start taking appropriate measures to counter prospective flood.

All the respondents expressed if the land was already saturated, it was unable to absorb further water after heavy rain. Furthermore, if river starts overflowing, the flood chances increase manifold. So, the pattern of rain in the village as well as in upstream areas matter a lot in predicting the floods. The announcement of the imminent flood is a regular practice, majority of the respondents told so. Irrespective of the fact that media warns the people living in the flood-prone areas in advance; however, the village has the tradition of drum beating as well. A person is dedicated to beat the drum and announce the imminent flood to take necessary safety measures. The person walks through every main street and make announcement with high pitch of his voice. People gather around him to receive message. Besides, there is an announcement in the mosque as well. A person is constantly assigned to watch the protective wall along the river.

\subsection{Building structure saving strategies}

Many elders told that the village had been established on a higher place because of the geographic location as it was situated in flood prone area. This higher place protects people and their houses from flood intensity. That is why all the old building structures were built on higher places in the village. The mosques, schools, old homes and many other buildings are built at higher and safer places. Besides, streets are designed in a very different way. For example, the streets are straight. They start from river side. Houses court yards are elevated at least five feet above the level of streets. When the flood hits the village, water flows smoothly from river side and crosses the village. The Streets of village seems streams. The flood water flows into the village and passes through the straight streets. Therefore, the location of the village and layout of the houses and streets help reducing the damages in during the flood.

Besides, the construction material used for building various structures is also different from that of other surrounding villages in the area. A local mason told that he uses the different ratio of sand and cement items to prepare concrete mixture to build structures in this village. However, he uses low ratio of different sand and cement items in the mixture in nearby villages where there is no risk of floods. In Khursheed, more cement and iron is used in preparing concrete structures. Similarly, excessive water showering is carried out on freshly built buildings to strengthen it. These concretes are more resilient against flood water. However, the cost of construction is very high here in this village as compare to other villages which are not the victim of floods. 
Besides, the size of the Bricks is also bigger and it is harder than those of used in other villages. This typical Brick size and structure enhance the strength, longevity and sustainability of the buildings. The foundation of the buildings goes five to six feet deep into the earth. This deep dig foundation provides stability to the building erected on it. Similarly, the width of the foundation $\mathrm{n}$ under the surface and three feet above the surface is around three feet. These strong foundation ns of buildings are resilient enough to stand firm during floods. In the village, construction cost is the major expenditure by the people to sustain in the expected floods.

\subsection{Livestock saving strategies}

All the respondents told that, conventionally in the village, agriculture is the major source of survival strategy to counter food security during floods. Some certain vegetables are planted like pumpkins, maize, beans, cabbage, spinach, potatoes, tomatoes and onions to meet the meat deficiency. Besides, sugarcane, citrus and rice are the major crops in the area. Sufficient food availability increases the resilience and resistance of the victims to fight against disaster. All these crops are more resilient to flood water. Similarly, these crops can be stored for some days to cook later. These crops maintain their freshness and contain good nutritious strength. All the respondents told that their stores were on first floor of the house. They store their dry ration and valuables even in the days when there is no risk of floods. During flood days, family members shift to first floor of the house as a safety and security measure.

On the first floor of the house a small cage type structured is built for hen etc. Besides, goats and sheep are also shifted to first floor of the house. There are some higher places in the village for cattle refuge. These places are called 'Ucha Vehras'. Here cattle are shifted during the flood. These places are surrounded by tall trees and thatch wall. Some 'Chara' (diet) like 'bhoosa' and maize are stored for cattle here. There were some people who told that they sent their cattle to their relatives living in nearby villages. Generally, the Buffaloes which give milk are sent to the relatives as they have their off shoots as well. During flood, it becomes difficult to receive milk from the cows and buffaloes. Therefore, some of the owners send them to their relatives living in other villages or living in the same village but at higher places.

\subsection{Life saving strategies}

The respondents told that majority of the villagers stay in the village during floods, while, there are a few who flee their homes to stay in the city where they have their houses. Some people, however, are living at 'Deras' (farmhouses) which are located outside the village. These 'Deras' are generally more vulnerable to flood water. Therefore, the people living there move to the villa ge well before the flood hits the village. All the respondents told that almost all of men in the village know how to swim. This skill is acquired and honed as a sports and rescue strategy. The children living there play some water sports in the canals and river water to enhance the swimming skills. During flood the swimming skill saves and rescues people from flood. Besides, this very skill is used to cross the streets and approach some other houses in the village.

Besides, majority of the respondents expressed that people are fond of horses in the village. Every house owns a horse as well. They use it as a transport and for riding as a hobby. There is a popular sport of tent pecking in the village. When there is a flood, they use it to rescue and transport people and goods during floods. Besides, there are three boats as well. These boats are used to cross the river in normal days and during floods villagers use them to rescue people living outside the village. 
Many of the respondents responded that they cook some dry sweets. The main ingredients include flour, milk, butter and some dry fruits in it. These dry sweets are full of nutritious strength and long-lasting characteristics. The recipes and ingredients are indigenously available to cook such sweets. When there is a flood, these sweets are used by people to survive as there is no cooking on daily basis in every house. There is another tradition in the nearby villages that they send some cooked rice and other cooking items to the affected village. The food is transported through horses and boats. However, every household has its own arrangements to survive for a week or so. There is a tradition of preserving cooked food items before the expected flood. Majority of the people living in the village is practicing Islam and regularly offer prayers. All the people say that flood is an act of God. This belief system gives the locals a spiritual strength to fight against the disaster. This spiritual strength enhances the immune system of the people. As a result, people are in a better position to fight against diseases and hardships.

\subsection{Conclusion}

The bitter truth about rapid changes of anthropogenic origin is undeniable (Mushtaq et al., 2019). This phenomenon will speed up disasters on the face of the world. The scientists and the World Bank have warned that the potential victims are the countries which are already living in the disaster-prone regions of the world. Pakistan falls on third on the list of the most vulnerable countries which may be affected by climate change, caused by the global warming. Global warning has disturbed the climate pattern and has increased the frequency of floods significantly in Pakistan. Earlier, flood hit the flood prone areas after four to five years and since 2010 , it is hitting every year. Therefore, the loss of life and property has increased many folds. The government is unable to cope with this issue alone. Already, the governance issue is in trouble in Pakistan.

Pakistan is a traditional and conventional society. People who are living in disaster prone areas have developed and devised numerous methods to cope with the emergency situations. These methods are unique everywhere as every area has different socio-cultural, economic and ecological characteristics.

It is very important that this Indigenous Knowledge may be acknowledged and incorporated in local level disaster management policies and strategies. Because can reduce the losses it faces in every disaster. These methods are cost effective, readily available, easy to implement and reliable for the local communities. However, it would be worthwhile to integrate modern knowledge with the local one to handle the disasters.

\subsection{Recommendations}

The authorities need to acknowledge the indigenous methods of natives to counter floods. Similarly, the early warning systems devised locally should be acknowledged by the authorities as the people are comfortable with them. And this local warning system can be further developed with the help of modern techniques. The huge gulf of information and coordination among different stake holders in disaster prone areas should be minimized through an effective coordination and communication at international, national and community level. One most effective tool for the revival and application of indigenous knowledge is education, which can reduce the gap between indigenous knowledge and modern techniques through institutional set up 
at regional, national and international level. Similarly, data base of Indigenous Knowledge can be created and linked to the educational system at different levels via networks and Global Information System (GIS).

\section{References}

Abid, M., A.Schneider, U., \& JürgenScheffran. (2016)(a). Adaptation to climate change and its impacts on food productivity and crop income: Perspectives of farmers in rural Pakistan. Journal of Rural Studies, vol 47, 254-266.

Abid, M., Scheffran, J., Schneider, U. A., \& Ashfaq, M. (2016)(b). Farmers' perceptions of and adaptation strategies to climate change and their determinants: the case of Punjab province, Pakistan. Earth Sciences Dynamic, vol 6, 225-243.

Abid, M., Schilling, J., Scheffran, J., \& Zulfiqar, F. (2016). Climate change vulnerability, adaptation and risk perceptions at farm level in Punjab, Pakistan. Science of The Total Environment, Volume 547, 447460.

Ali, K., \& Bajracharyar, R. M. (2017). Advances and Challenges in Flash Flood Risk Assessment: A Review. Journal of Geography \& Natural Disasters, 2-8.

Batool, Z. (2017). Flood Frequency Analysis of Stream Flow in Pakistan Using LMoments. International Journal of Advance Research, Ideas and Innovations in Technology, Volume3, Issue4, 136-143.

Butt, A., Khan, A., \& Ahmad, S. S. (2015). Evaluation of increasing susceptibility of areas surrounding Kala Bagh Dam, Pakistan to flood risk: A review. Middle East Journal Of Business - Volume 10, Issue 2, 27-33.

Cheeseman, J. (2016). 7 - Food Security in the Face of Salinity, Drought, Climate Change, and Population Growth. Halophytes for Food Security in Dry Lands, 111-123.
Cheong, J., Kwak, D., \& Haishan Yuanb. (2017). Trade to aid: EU's temporary tariff waivers for floodhit Pakistan. Journal of Development Economics Volume 125, 70-88.

Ganchi, Shakoor, Thaver, Khan, M., \& Janjua, A. (2016). Current situation and challenges in implementing Malaria control strategies in Pakistan. Journal Critical Reviews in Microbiology Volume 42, Issue 4, 23-45.

Hassan, G., \& Hassan, F. (2017). Sustainable use of groundwater for irrigated agriculture: A case study of Punjab, Pakistan. European Water 57, 475-480.

Jabeen, A., Huang, X., \& Aamir, M. (2015). http://file.scirp.org/pdf/JWARP_2015123113503659.p dfThe Challenges of Water Pollution, Threat to Public Health, Flaws of Water Laws and Policies in Pakistan. Journal of Water Resource and Protection, 7, 15161526.

Khan, M. A., Khan, J. A., Ali, Z., Ahmad, I., \& Ahmad, M. N. (2016). The challenge of climate change and policy response in Pakistan. Environmental Earth Sciences, 211-224.

Kumbhar, A. S., Magsi, H., Kumbhar, M. I., \& Rind, Z. K. (2018). Status of Population Growth and Food Sustainability in Pakistan. Indian Journal of Science and Technology, Volume 11, Issue 16, 211-223.

Mahmood, A. (2017). Flood Hazard Mapping in Integrated Flood Risk Management: Importance and Problems Associated to Pakistan. Pakistan: National University of Science and Technology .

Main, M. A., Saleh, A. J., Weshahi, Y. A., GerdRüdiger, Maurizio, B., Flood, C. J., . . . Kvien, T. K. (2015). The global challenges and opportunities in the practice of rheumatology: White paper by the World Forum on Rheumatic and Musculoskeletal Diseases. Clinical Rheumatology, Volume 34, Issue 5, 819-829.

Memon, A. H., Ghanghro, A. B., Jahangir, T. M., Younis, M., \& Lund, G. M. (2016). During and Post Flood Health Impacts of Dissolved Metals on Adjacent Area of Manchur Lake, District Jamshoro, Sindh, Pakistan. Biomedical Letters, Volume 2 , Issue $1,38-45$. 
Mohamed I. K., Razali S. \& Mushtaq A. (2019). Impacts of change management on risk and cost management of a construction projects. Journal of Project Management 4 (2019) 157-164.

Munir, B. A., \& Iqbal, J. (2016). Flash flood water management practices in Dera Ghazi Khan City (Pakistan): a remote sensing and GIS prospective. Natural Hazards, Volume 81, Issue 2, 1303-1321.

Mushtaq A. Salmia B. Zarina I. \& Firas B. I. A. (2019). State of the Art Compendium of Macro and Micro Energies. Advances in Science and Technology Research Journal. Volume 13, Issue 1, March 2019, pages 88-109.

Qasim, M., Siddiqua, A., Sadef, Y., Bashir, A., Khalid, M., Naveed, M., Ali, S. ( 2017 ). Climate Change: Potential Health Effects on Vulnerable Population \& Malnutrition Food Security Challenges: A Case Study of Shakargarh. Journal of Applied Environmental and Biological Sciences, 7(10), 180188.

Qasim, S., Qasim, M., Shrestha, R. P., \& Khan, A. N. (2017). An assessment of flood vulnerability in Khyber Pukhtunkhwa province. Environmental Sciences, 4(2), 206-216.

Raza, H., Ahmed, F., Mohiuddin, Z. A., \& Osama, A. (2017). Mitigating Financial Burden of Elderly through Social Protection Schemes: Issues and Challenges for Pakistan. International Journal of Emerging Trends in Social Sciences, Vol. 1, No. 2, 81-89.

RehmanTariq, M. A., \& Giesen, N. d. (2012). Floods and flood management in Pakistan. Physics and Chemistry of the Earth, Parts A/B/C Volumes 47-48, 11-20.

S.Chaudhury, A., J.Ventresca, M., F.Thornton, T., Helfgott, A., Sov, C., Barald, P., . . . Ligthart, J. (2016). Emerging meta-organisations and adaptation to global climate change: Evidence from implementing adaptation in Nepal, Pakistan and Ghana. Global Environmental Change Volume 38, 243-257.

Shah, M., Rahman, A., \& Chowdhury, S. (2015). Challenges for achieving sustainable flood risk management. Journal of Flood Risk Management, 352-359.

Shakir, A. S., Rehman, H. -u., \& Ehsan, S. (2010). Climate Change Impact On River Flows In Chitral
Watershed. Pakistan Journal of Engineering and Applied Sciences, 12-23.

Zaheer, M., Ahmad, Z., \& Shahab, A. (2016). Hydrological Modeling and Characterization of the Khanpur Watershed, Pakistan. American Water Works Association, 262-269.

Zarmina, \& Zarmina, N. (2014). Flood Management System In Pakistan. Pakistan: National University of Science and Technology. 